\title{
PERSEPSI KRISTEN TERHADAP KEHIDUPAN MODERN
}

\author{
Adenan \\ Universitas Islam Negeri Sumatera Utara (UINSU) Medan \\ adenan@uinsu.ac.id
}

\begin{abstract}
Abstrak
Gerakan modersnisasi membawa Barat kepada kehidupan baru yang lebih modern dan berteknolgi yang dapat mempengaruhi dunia secara global, bukan saja dari sisi pembangungan material, struktur dan infastruktur tapi juga perubahan metode berfikir, gaya hidup, cara berpakaian, berpolitik, berekonomi hingga bergeser kepada cara sudut pandang serta pandangan hidup masyarakat yang merembes pada bergesernya doktrinitas agama. Agama Kristen yang diwakili gereja dengan gerakan reformasi modern melahirkan pengaruh yang sangat kuat pada agama Nasrani itu sendiri, sehingga menimbulkan pertarungan fisik antara pihak gereja dan pendukung modersisasi. Yang menelan banyak korban jiwa, seperti melakukan pembakaran brutal, terhadap para tokoh pemikir dan para pendeta.
\end{abstract}

Kata Kunci : Kristen, Modern, Persepsi.

\section{Abstract}

The modernization movement brings the West to a new, more modern and bigh-tech life that can affect the world globally, not only in terms of material development, structure and infrastructure, but also changes in thinking methods, lifestyles, ways of dress, politics, economics to shift to the perspective and the view of people's life that seeps on the shifting of religious doctrine. The Christian religion represented by the church with the modern reform movement gave a very strong influence on Christianity itself, causing physical battles between the church and supporters of moderation. Which claimed many lives, such as the brutal arson, of thinkers and priests.

Keywords: Christian, Modern, Perception.

\section{Pendahuluan}

Modernisasi Barat yang mencapai kegemilangannya pada abad 18 M setelah mengalami proses pencerahan (reniasance) dan setelah mengalami abad kebodohon (Dark ages) selama ribuan tahun, kini Barat mengalami perubahan yang sangat menakjubkan. Gerakan modersnisasi membawa Barat kepada kehidupan baru yang lebih modern dan berteknolgi yang dapat mempengaruhi dunia secara global, bukan saja dari sisi pembangungan material, struktur dan infastruktur tapi juga perubahan metode berfikir, gaya hidup (life style), cara berpakaian, berpolitik, berekonomi hingga bergeser kepada cara sudut pandang serta pandangan hidup masyarakat yang merembes pada bergesernya doktrinitas agama.

Perubahan-perubahan itu pada satu sisi memberikan keuntungan kepada manusia, serta dapat menikmati fasilitas modern yang memudahkan segala urusan, namun pada sisi lain yang 
tidak boleh dipandang remeh adalah efek negatif dari modernisasi yang masuk pada wilayah teologi yang menjadi sebuah pemahaman modernisme yang merubah cara sudut pandang ketuhanan dan agama menurut cara sudut pandang modernis Barat.

\section{Mengenal Agama Kristen}

\section{Sekilas tentang agama Kristen}

Agama Kristen (Nasrani) adalah istilah khusus dalam Alquran terhadap ajaran Nabi Isa As untuk masyarakat Yahudi. Tetapi karena orang-orang Yahudi tidak mau menerimanya maka sepeninggal Nabi Isa As., ajaran tersebut disebarkan dimasyarakat luar Yahudi. Agama Kristen lahir di kota Nazaret Palestina yang dibawa dan dkembangkan oleh Nabi Isa As. Nabi Isa As dalam agama dunia Kristen dikenal dengan Yesus Kristus (Michel Keene, 2006 : 38). Umat Kristen percaya bahwa Yesus Kristus adalah putra Allah. Bahkan menurut keyakinan umat Kristen bahwa Tuhan satu beroknum tiga, ialah Bapa putra, dan Roh Kudus (Tritunggal). Umat Kristen (Nasrani) mengaku bahwa setiap oknum adalah Allah yang sesungguhnya. Kesemuanya bersifat kekal, abadi dan mahasempurna, antara satu dan lainnya sama derajatnya, dan terpatri dalam satu kesatuan yang utuh.

Menurut Michael Chene sekarang ini agama Kristen merupakan agama terbesar didunia, dengan perkiraan jumlah penganutnya sebanyak 2 milyard orang, walaupun jumlah itu terbagi dalam lebih dari 20 ribu sekte atau gereja. Sekte yang paling besar gereja Katholik Roma dengan jumlah 1,2 Milyard umat, diikuti oleh banyak gereja Protesten dengan jumlah seluruhnya 360 juta umat, dan gereja ortodok dengan jumlah 170 juta umat. Gereaja Protestan terbesar adalah gereja Anglikan denganjumlah 80 juta umat.

\section{Inti ajaran Kristen}

Ada beberapa inti ajaran agama Kristen yaitu:

a. Trinitas adalah 1 Allah 3 pribadi yaitu Allah Bapa, Allah Putra dan Allah Roh Kudus.

b. Bagi umat Katholik dan ortodok, prawan Maria mendapat status yang jauh sekedar di atas ibu Yesus. Mereka percaya bahwa ia mengandung Yesus secara adi kodrati dengan perantaraaan Roh Kudus.

c. Yesus penjelmaan Allah, melalu tiang salib dosa manusia ditebuskan, penebusan dosa merupakan rekonsiliasi antara Allah dengan manusia yang di dapatkan melalui kematian dan kebangkitan Yesus.

d. Banyak umat Kristen memegang teguh Al-Kitab adalah wahyu Allah tanpa cacat yang mempunyai kewenangan dalam segala hal tentang iman dan tingkahlaku manusia. 
Masih banyak lagi ajaran iman Kristen yang lain seperti adanya dosa warisan atau turunan, kebangkitan kembali, yakni bangkit dari segala orang mati, dan lain-lain. Demikian halnya ibadat umat Kristen seperti sakramen, komuni, ibadat dan doa, hari raya dan lain-lain sebagainya, bahkan ada 10 perintah Allah merupakan inti ajaran Kristen, khususnya gereja Katolik yang dikenal dengan ten commandement (Abdullah Ali, 2007 : 138-139).

\section{Sekte-sekte dalam Kristen Protestan}

Dalam agama Kristen Protestan ada beberapa sekte-sekte (Abdullah Ali, 2007 : 144) (golongan) yakni:

a. Gerakan Pentakosta; menurut sekte ini bahwa keselamatan seseorang bukan semata-mata karena anugerah yang diterima sebagai kepercayaan, melainkan juga harus menerima pemandian roh, melalui tanda-tanda penglihatan serta pemberian lidah dalam bentuk informasi.

b. Sevenh day Adventists, sekte ini menjelaskan bahwa keselamatan seseorang bukan hanya terletak pada anugrah melainkan pada kesedihan mengganti hari Minggu dangan perayaan hari Sabtu.

c. Saksi Yahovi; sekte ini berpendapat bahwa untuk mendapatkan kerajaan Allah, seseorang harus menggabungkan diri dengan saksi Yahova serta menjauhkkan diri dari saksi Yahova, serta menjauhkan diri dari kegiatan-kegiatan politik, komersial dan Negara.

d. Cristian Science; sekte ini mengatakan bahwa untuk memperoleh keselamatan dan anugerah, seseorang harus sampai pada tarap pemikiran tentang kematian, penyakit dan materi sebagai imaginasi (khayalan) belaka.

e. Sekte Norman; bahwa seseorang yang menginginkan kemuliaan surga, harus memenuhi 4 hukum Injil yakni, iman, azab, pembaptisan dan penumpangan tangan.

\section{Agama Kristen dan Modernitas}

Respon agama Kristen terhadap modernitas sangat marak diperbincangkan dikalangan para sosiolog, filosof dan pemikir keagamaan. Dalam Encyiclopedia Americana dijelaskan bahwa modenisasi agama diartikan pemikiran agama yang berangkat dari keyakinan bahwa kemajuan sains dan kebudayaan modern menuntut adanya reisnterpretasi terhadap agama klasik sesuai pemikiran filsafat. Dengan demikian, doktrin modernisasi adalah teks wahyu dibawah sain, teks agama harus ditafsir ulang agar sesuai dengan zaman (tt.,Encyclopedia Americana, 1972).

Istilah ini dinisbahkan kepada gerakan protes gereja Katolik Roma terhadap otoritas gereja konserfatip. Gerakan yang berupa protes, ini juga dipakai untuk gerakan liberalism dalam Kristen Protestan. Sebelumnya gerakan liberalism agama lebih dahulu dipelopori oleh Yahudi, hanya saja Yahudi tidak memakai istilah modernisme. Istilah ini dikenal dalam agama Kristen. 
Jadi pada saat itu modernisasi adalah istilah lain dari liberalisasi. Munculnya modernisasi di Eropa bukan tanpa persoalan bagi agama Kristen. Pergeseran teologi dan perubahan cara sudut pandang adalah hasil adapsi modernisasi Barat yang menggiurkan, karena orientasi modernisasi Barat memiliki terminologi khusus yaitu modernisasi paham Agama.

Cara sudut pandang barat tentang agama disamakan dengan cara pandang mereka tentang filsafat yang senantiasa berubah-ubah sesuai dengan perkembangan gaya berfikir dan zaman. Sehingga definisi modern yang di buat oleh barat sesuai dengan keinginanan dan orientasi mereka.

Secara etimologi barat mendefinisikannya "using news style or ways of thinking" atau "to change so that it use new equipment or new ideas". Definisi diatas memiliki makna yang komprehensif yang bukan saja berhubungan dengan perubahan gaya hidup (life style) atau perubahan alat-alat kuno menjadi modern, akan tetapi juga perubahan cara berfikir (new ways of thinking) dan perubahan cara sudut pandang (new ideas). Dari sinilah dapat kita ketahui bahwa stresing utama modrenisasi Barat adalah perubahan cara sudut pandang terhadap agama, karena historis munculnya modernisasi itu sendiri adalah penolakkan masyarakat barat terhadap Agama khususnya Kristen.

Pergulatan antara gereja dengan gerakan reformasi modern melahirkan pengaruh yang sangat kuat pada agama Nasrani itu sendiri, sehingga menimbulkan pertarungan fisik antara pihak gereja dan pendukung modersisasi. Yang menelan banyak korban jiwa, seperti melakukan pembakaran brutal, terhadap para tokoh pemikir dan para pendeta, dari tahun $1481 \mathrm{M}$. pendukung gerakan modernism telah berhasil membakar hidup-hidup 10.220 orang dan mebantai 61.860 lainya, 970.23 lainya mereka siksa bahkan merekapun membakari kitab Taurat yang berbahasa Ibrani.

Awal dari ketidakpercayaan masyarakat Barat terhadap gereja salahsatunya adalah bermula pada problem teks bible, siapa yang menulis bible itu (who wrote the bible?) sebenarnya, kemudian hubungan antara teks bible dan sains, walaupun interpretasi bible secara rigid dan litreral dengan dukungan teology sekalipun masih belum mampu menghadapi perkembangan sains yang terjadi diluar gereja.

Salah satu contoh ketidakmampuan gereja mengahadapi sains adalah pernah menghukum ilmuwan seperti Galileo Galilei (1564-1642) karena mengekspos teori "bahwa matahari adalah pusat tata surya (heliocentric). Hal itu dilakukannya untuk mempertahankan hegemoni kekuasaan gereja yang memiliki doktrin bahwa gereja tidak pernah salah (infallibility) karena merupakan wakil Kristus dimuka Bumi (Richard Tarnas, 1991 : 300). Otoritas gereja yang tidak ilmiah ini membuat masyarakat Barat berontak, dan pada perkembangannya gereja 
akur dibawa arus modernisasi barat yang mengakui elastisisitas agama dalam menghadapi perkembangan zaman, lalu melakukan keritik terhadap ajaran Taurat dan Injil dalam bingkai penelitian (kritik historis) (Richard, 1991 : 300).

Menurut Karen Amstrong dalam bukunya The Battle for God; Para Ilmuan pada masa awal modern memandang penelitian dan perbincangan ilmiah dalam kerangka agama dan mitologi meyakini bahwa sains lebih bersifat ilahiah ketimbang insaniah. Bagaimana pun juga, teori tentang alam semesta yang heliosentris adalah pukulan yang mengguncangkan persepsi mitologi lama. Hipotesisnya begitu radikal, sehingga sedikit sekali orang pada zamannya yang menerimanya. Copernicus menyatakan bahwa bumi bukanlah pusat tata surya. Bumi dan planet lainnya yang sebenarnya mengelilingi matahari. Jika kita memandang langit dan mengira bahwa langit bergerak, maka itu sebenarnya adalah hasil dari rotasi bumi yang berotasi ke arah yang berlawanan (Karen, 2000 : 104).

Teori Copernicus ini memang tidak sempurna, namun fisikawan Jerman Johanes Kepler (1571-1630) memberikan bukti matematis untuk mendukung teori Copernicus tersebut. Seperti juga sudah dijelaskan, astronom Galileo Galilei (1564-1642) menguji hipotesis Copernicus secara empiris dengan mengamati planet-palanet dengan menggunakan teleskop ciptaannya yang telah disempurnakan. Ketika Galileo Galilei mempublikan temuannya pada tahun 1642, dia menjadi figure sensasional. Di seluruh Eropa, orang-orang mulai membuat teleskop untuk memandang langit. Galileo di bungkam oleh program inkuisisi. Ia dipaksa menelan ucapannya. Kelakuannya yang temperamental semakin membuat deras hujatan terhadapnya.

Benturan pemikiran dan fisik yang terjadi di barat pada saat munculnya gerakan modernisasi, sebab utamanya karena kalangan modrenis menganggap bahwa gereja membekukan otoritas intelektual selain segala kebijakan gereja menjadi kebenaran absolute. Mereka menganggap bahwa agama mereka tidak memberi posisi kepada akal dan tidak sesuai dengan perkembangan zaman. Kondisi traumatis di dunia Barat mendesak mereka untuk melakukan perubahan terhadap agama, seperti menempatkan Agama Kristen sebagai agama personal dan membatasi wilayah kekuasaanya, dan melakukan proses libralisasi serta merubah (dekontrusi) besar-besaran terhadap doktrin Kristen.

Dalam bidang politik, mereka melahirkan kosep sekularisme, dalam bidang teology, mereka mengembangkan konsep teologi terbuka (inklusif) dan persamaan (pluralis), yang menolak kleim Kristen sebagai satu-satunya Agama yang benar. Dalam bidang organisasi keagamaan, mereka menghantam 'formal religion' dan mengembangkan konsep agama sebagai aktivitas, dalam bidang kajian kitab suci, mereka mengembangkan metode interpretasi 
'bermeneutika' yang mendekontruksi konsep bible sebagai "the words of God" dan mengembangkan metode historical criticism (kritik Historis) terhadap Bible. Proses modernisasi Barat adalah usaha memodernisasikan agama, mendesak agama agar sesuai dengan keinginan dan kebutuhan manusia. Jadi Agama yang mesti mengikuti perubahan dan perkembangan zaman, jika teks Agama (kitab suci) tidak sesuai dengan konteks zaman, maka teks itu tidak perlu dipakai, bahkan melakukan dekonstruksi teks agar sesuai dengan konteks zaman (Karen, 2000 : 104).

Bagi modernis Barat, yang tidak melakukan perubahan terhadap Agama adalah Fundamentalis, yang benci dengan modrenisasi dan perkembangan. Maka dibuatlah definisi fudamentalis sebagai masyarakat beragama yang benci terhadap modern'. Seperti yang didefinisikan oleh Karen Amstrong yang memandang fundamentalisme sebagai bentuk spiritualitas yang disajikan untuk melawan (embattled), yang muncul sebagai respon atas krisis yang dirasakan.

Dalam buku Advancement of Leaning karangan Francis Bacon (1561-1626) yang merupakan penasehat Raja Inggris James I Bacon, berpendapat bahwa semua kebenaran, bahkan doktrin agama yang paling sacral sekalipun, harus tunduk kepada metode kritis sains empiris, jika kebenaran kontradiktif dengan fakta-fakta dan bukti dan pengamatan indra kita, maka kebenaran itu harus disingkirkan. Tidak satu pengetahuan masa lampau pun yang dibolehkan mengahalangi proses penciptaaan masa depan baru yang agung bagi kemanusiaan. Bacon menuntut adanya kebebasan intlektual sebebas-bebasnya bagi pengebdi pengetahuan yang karyanya terlalu penting bagi umat manusia untuk mengahalangi para agamawan gereja yang berpikiran sempit (Karen, 2000 : 109). Pada abad ke 17, para ilmuasn Eropa mulai melepaskan diri dari ikatan lama, mereka tidak memerlukan itu, Bacon berpendapat bahwa hanya sains yang benar. Orang-orang yang ingin menganut gaya hidup rasional, namun juga religius, ia harus mencari cara baru berpikir tentang Tuhan dan spiritualitas (Karen, 2000 : 109).

Para filsuf Prancis dan Jerman yang menganut faham rasional, menganggap agama wahyu (Kristen) dan mitologi lama sebagai sesuatu yang using dan ketinggalan zaman, karena menurutnya rasio merupakan satu-satunya objektolok ukur kebenaran, maka agama-agama lama yang berdasarkan pada konsep fiktif "wahyu" dianggap versi naif dari agama rasio tersebut dan karenanya harus disingkirkan. Agama haruslah rasional ucap teolog Matthew Tindal (1655-1673) dan teolog Irlandia John Toland. Rasio kita adalah satu-satunya cara untuk sampai kepada kebenaran yang sacral., sehingga agama Kristen harus dibersihkan dari hal-hal yang berbau supernatural, mukjizat dan misterius. Wahyu tidak penting karena manusia dapat sampai kepada kebenaran hanya dengan mengandalkan kekuatan rasionya (John, 1989 : 66-69). Lagi menurut John Toland, pantulan dunia fisik memberikan bukti tak terbantahkan tentang adanya Tuhan 
dan Sebab Pertama. Begitu juga Herman Samuel Reimarus (1694-1768) seejarawan Jerman menyatakan bahwa Yesus tidak pernah mengklaim dirinya sebagai Tuhan, dan bahwa ambisi Yesus sebenarnya adalah ambisi politik. Yesus seharusnya cukup dianggap sebagai seorang guru besar, pendiri dari sebuah agama yang sederhana, agung luar biasa, dan praktis (John, 1989 : 101).

Pada tahun 1882, Friedrich Nietzsche (1844-1900) memproklamirkan bahwa Tuhan telah mati. Dalam The Gay Science, dia menceritakan kisah seorang yang gila yang berlari ke pasar ramai sambil berteriak "Aku melihat Tuhan!" Lalu, ketika orang-orang yang ada di sana menanyainya apakan dia membayangkan Tuhan pindahatau lari, orang gila itu memandangi mereka. "Ke mana Tuhan pergi?" tanya dia dengan heran atas pertanyaan orang-orang itu. "Kita telah membunuh-Nya! (Friedrich, 1974 : 181).

Dalam maksudnya yang penting, dengan menjadikan Tuhan itu murni rasional, yaitu dengan berusaha mencapai Tuhan semata-mata melalui intlek seperti yang dilakukan umat modern, manusia sama saja membunuh Tuhan. Nietzsche percaya bahwa kematian Tuhan telah mencabut manusia dari akarnya, melempar bumi keluar dari orbit dan mengembangkannya di dalam semesta yang tak berjalur. Semua hal memberikan arah bagi manusia telah hilang, terror mendalam serta perasaan tanpa makna dan kehancuran menjadi bagian dunia modern. Hal ini tidak hanya mempengaruhi umat Kristen Eropa, Umat Islam dan Yahudi, sama-sama terisap dalam pusaran proses modrnisasi dan merasakannya sebagai hal yang membingungkan (Karen, 2000 : 150). Disini nampak apa yang dimaksud Karen Amstong adalah bentuk kekhawatiran bahwa modernitas akan mengikis bahkan memberangus keyakinan (relegius) dan moralitas.

\section{Penutup}

Dari uraian-uraian tersebut di atas ada beberapa kesimpulan bahwa agama Nasrani (Kristen) yang diturunkan kepada Nabi Isa esensi ajarannya tertuang dalam ajran trinitas; satu Allah tiga pribadi yaitu Allah Bapa, Allah Putra dan Allah Roh Kudus. Prawan Maria mendapat status yang jauh sekedar di atas ibu Yesus. Mereka percaya bahwa ia mengandung Yesus secara adi kodrati dengan perantaraaan Roh Kudus. Yesus penjelmaan Allah, melalu tiang salib dosa manusia ditebuskan, penebusan dosa merupakan rekonsiliasi antara Allah dengan manusia yang di dapatkan melalui kematian dan kebangkitan Yesus. Banyak umat Kristen memegang teguh Al-Kitab adalah wahyu Allah tanpa cacat yang mempunyai kewenangan dalam segala hal tentang iman dan tingkahlaku manusia. Respon Kristen yang diwakili gereja dengan gerakan reformasi modern melahirkan pengaruh yang sangat kuat pada agama Nasrani itu sendiri, sehingga menimbulkan pertarungan fisik antara pihak gereja dan pendukung modersisasi. Yang menelan 
banyak korban jiwa, seperti melakukan pembakaran brutal, terhadap para tokoh pemikir dan para pendeta.

Ketidakpercayaan masyarakat Barat terhadap gereja salahsatunya adalah bermula pada problem teks bible, siapa yang menulis bible itu (who wrote the bible?) sebenarnya, kemudian hubungan antara teks bible dan sains, walaupun interpretasi bible secara rigid dan litreral dengan dukungan teology sekalipun masih belum mampu menghadapi perkembangan sains yang terjadi diluar gereja. Contoh ketidakmampuan gereja mengahadapi sains adalah pernah menghukum ilmuwan seperti Galileo Galilei (1564-1642) karena mengekspos teori "bahwa matahari adalah pusat tata surya (heliocentric).

Benturan pemikiran dan fisik yang terjadi di barat pada saat munculnya gerakan modernisasi, sebab utamanya karena kalangan modrenis menganggap bahwa gereja membekukan otoritas intelektual selain segala kebijakan gereja menjadi kebenaran absolute. Mereka menganggap bahwa agama mereka tidak memberi posisi kepada akal dan tidak sesuai dengan perkembangan zaman. Kondisi traumatis di dunia Barat mendesak mereka untuk melakukan perubahan terhadap agama, seperti menempatkan Agama Kristen sebagai agama personal dan membatasi wilayah kekuasaanya, dan melakukan proses libralisasi serta merubah (dekontrusi) besar-besaran terhadap doktrin Kristen.

Jadi Agama (Kristen) yang mesti mengikuti perubahan dan perkembangan zaman, jika teks Agama (kitab suci) tidak sesuai dengan konteks zaman, maka teks itu tidak perlu dipakai, bahkan melakukan dekonstruksi teks agar sesuai dengan konteks zaman.

\section{Daftar Pustaka}

Ali Abdullah , Agama dalam Perbandingan, (Bandung: Nuansa Aulia 2007).

Amstrong, Karen, The Battle for God, Cet. I, (New York: Alfred A. Knoft, 2000).

Armas, Adnin, Pluralisme Agama, (Jakarta: Insists, 1434 H.).

Encyclopedia Americana, Vol. 19, (New York: Americana Corp, 1972).

Elga, Sarapung, Sejarah Teologi dan Etika Agama-agama, Yogyakarta: Pustaka Pelajar, 3003.

Keene, Michel, Agama-agama Dunia, Hinduisme, Yudaisme, Buddhaisme, Kristianitas, Islam, Sikhisme, Konsfusianisme, Tosime, Zoroastrianisme,m Shintoisme, Kepercayaan Bahai, (Yogyakarta: Kansius, 2006).

Mansur, Sufaat, Agama-agama Besasr Masa Kini, (Yogyakarta: Pustaka Pelajar, 2011).

Harahap, Syahrin, Teologi Kerukunan, Cet. I, (Jakarta: Prenada Media Group, 2011).

Hitti, Philip, K, Hitory of the Arabs, (London: Macmillan Press, 1994). 
Hidayat, Komaruddin, Konflik, Agama-agama, (Sinar Medan: 21 Januari 2000).

Karel, A, Steenbrink, Dialog Antar Agama Pristiwa atau Proses,(Republika: 6 Maret 1998).

Rudavsky, David, Modern Jewish Religion Movement: A History of Emancipation and Adjustment, (New York: 1967).

Sofyan, Muhammad, Agama dan Kekerasan dalam Bingkai reformasi, (Yogyakarta: Media Prasind, 1999).

Toland, John, Christianity Not Mysterious, (Chicago: 1989)Friedrich Nietzsche, The Gay Science, (New York: 1974).

Th, Van, Leeuwwn, Aren, Cristendom in the Werelgescheidenis (Agama Kristen dalam Sejarab Dunia), Terj. Frits M. Kirihio, Cet. 12, (Jakarta: Gunung Mulia, 2012).

Tarnas, Richard, The Passion of the Westerm Mind, (New York: 1991). 